\title{
The Prognostic Impact of Absolute Lymphocyte and Monocyte Counts at Diagnosis of Diffuse Large B-Cell Lymphoma in the Rituximab Era
}

\author{
Kazunari Aoki Sumie Tabata Noboru Yonetani Akiko Matsushita \\ Takayuki Ishikawa \\ Department of Hematology and Clinical Immunology, Kobe City Medical Center General Hospital, Kobe, Japan
}

\section{Key Words}

Diffuse large B-cell lymphoma · Lymphocyte · Monocyte · Rituximab

\begin{abstract}
Background: A recent report showed that the combination of the absolute lymphocyte count (ALC) and the absolute monocyte count (AMC) at diagnosis gave a prognostic score in diffuse large B-cell lymphoma (DLBCL). However, this model requires validation in other patient cohorts. Methods: We retrospectively evaluated the prognostic impact of the combination of the ALC and the AMC at diagnosis in a cohort of 299 DLBCL patients who were treated in the rituximab era at a single institution. Results: In univariate analyses, an ALC $\leq 1.0 \times 10^{9} /$ l [4-year overall survival (OS) rate 47.0 vs. 79.4\%; $<<0.001$ ] and an AMC $\geq 0.63 \times 10^{9} /$ l (4-year OS rate 52.4 vs. $75.6 \% ; p<0.001)$ were associated with inferior OS, respectively. In multivariate analyses, an ALC $\leq 1.0 \times 10^{9} / \mathrm{I}$ and an $A M C \geq 0.63 \times 10^{9} /$ I were significantly associated with inferior OS independently of the International Prognostic Index. Furthermore, the combination of ALC and AMC could identify patients with the dismal prognosis; the 4-year OS rates for patients with $\mathrm{ALC} \leq 1.0 \times 10^{9} / \mathrm{I}$ and $\mathrm{AMC} \geq 0.63 \times$ $10 \%$ / were $18.8 \%$. Conclusions: The combination of ALC and AMC at diagnosis may be useful for the prognostic stratification of patients with DLBCL.

Copyright $\odot 2013$ S. Karger AG, Basel
\end{abstract}

(c) 2013 S. Karger AG, Basel

0001-5792/13/1304-0242\$38.00/0

\section{Introduction}

The International Prognostic Index (IPI), established in 1993 to aid prognosis prediction in patients with diffuse large B-cell lymphoma (DLBCL) receiving treatment with cyclophosphamide, doxorubicin, vincristine and prednisolone (CHOP) or other $\mathrm{CHOP}$-like regimens, remains valid in the rituximab era; however, the 3-year overall survival (OS) rate for patients with a high-risk IPI (H-IPI) is around 60\% [1]. Therefore, a new risk stratification system, which can identify patients with the dismal prognosis, is required.

Recently, gene expression profiling studies in nonHodgkin lymphomas showed that the genes expressed by tumor-infiltrating lymphocytes and myeloid-derived cells predict clinical outcomes and indicate that factors related to the host's adaptive immunity and the tumor microenvironment are significant prognostic variables in non-Hodgkin lymphomas [2,3]. Furthermore, Wilcox et al. [4] reported that in patients with DLBCL, the combination of the absolute lymphocyte count (ALC) and the absolute monocyte count (AMC) at diagnosis gave a prognostic score that was independent of the IPI; however, this model requires validation in other patient cohorts. Therefore, we retrospectively evaluated the prognostic impact of the ALC and the AMC at diagnosis in patients with DLBCL receiving treatment in the rituximab era.

\section{KARGER}

E-Mail karger@karger.com

www.karger.com/aha
Dr. Kazunari Aoki

Department of Hematology and Clinical Immunology

Kobe City Medical Center General Hospital

2-1-1 Minatojima-minami-machi, Chuo-ku, Kobe 650-0047 (Japan)

E-Mail kazunariaoki0911@gmail.com 


\section{Patients and Methods}

Data from consecutive patients diagnosed with DLBCL at our hospital between 1 January 2004 and 31 January 2011, all of whom were treated with $\mathrm{CHOP}$ plus rituximab (R-CHOP therapy) with curative intent, were retrospectively evaluated. Patients with intravascular large B-cell lymphoma, primary effusion lymphoma or mediastinal B-cell lymphoma and patients with central nervous system involvement at diagnosis, patients with a history of indolent lymphoma and HIV-positive patients were excluded. This study was approved by the institutional review board of the Ethics Committee and complied with the Helsinki Declaration.

The primary outcome measure was OS. OS was defined as the time (in months) from the date of diagnosis to the date of death from any cause. The objective of the study was to determine the prognostic impact of the ALC and the AMC at diagnosis. ALC and AMC were obtained from a standard complete blood count and a differential was performed manually at the time of diagnosis. We used an ALC cutoff of $1.0 \times 10^{9} / 1$ and an AMC cutoff of $0.63 \times 10^{9} / 1$ because these cutoffs were used in the previous report [4].

Clinical features were compared between groups using the $\chi^{2}$ test, Fisher's exact test and Spearman's rank correlation. OS was estimated according to the Kaplan-Meier method, and the groups were compared using the log-rank test. The Cox proportional hazards model was used to estimate the hazard ratio (HR) and the corresponding 95\% confidence interval (95\% CI) using the lowrisk group as the reference. All reported $\mathrm{p}$ values were two-sided, and $\mathrm{p}<0.05$ was considered significant. All statistical analyses were performed using STATA (version 11.1; StataCorp., College Station, Tex., USA).

\section{Results}

In total, 229 patients were evaluated. The median follow-up period was 43.5 months (range 1-100) and the median age was 69 years (range 23-90).

The characteristics of the 229 patients are listed in table 1. One hundred and sixteen patients (50.7\%) had Ann Arbor stage III or IV disease, and 71 (31.0\%) had a performance status of $\geq 2$. Serum lactate dehydrogenase levels were higher than normal in 122 patients (53.3\%). The IPI was calculated as low risk (L-IPI) in 77 patients (33.6\%), low-intermediate risk (LI-IPI) in 57 patients (24.9\%), high-intermediate risk (HI-IPI) in 38 patients (16.6\%) and H-IPI in 57 patients (24.9\%), which was significantly higher than that in the patient cohort of the previous report [L-IPI in 104 patients (40.6\%), LI-IPI in 68 patients $(26.6 \%)$, HI-IPI in 59 patients $(23.0 \%)$, and $\mathrm{H}$-IPI in 25 patients (9.8\%); $\mathrm{p}=0.006$ )] [4]. The median ALC and AMC were $1.3 \times 10^{9} / 1$ (range 0.16-3.8) and $0.39 \times 10^{9} / 1$ (range $0-2.4$ ), respectively. Whereas the ALC in this patient cohort was similar to that in the pa- tient cohort in the previous report (median $1.2 \times 10^{9} / 1$, range $0.87-1.8$ ), the AMC in this patient cohort was lower than that in the patient cohort of the previous report (median $0.63 \times 10^{9} / 1$, range $0.47-0.83$ ) [4]. The unadjusted 4-year OS rates for the L-IPI, LI-IPI, HI-IPI and H-IPI patients were $86.5 \%(\mathrm{n}=77), 74.0 \%(\mathrm{n}=57)$, $65.1 \%(\mathrm{n}=38)$ and $48.3 \%(\mathrm{n}=57)$, respectively $(\mathrm{p}<$ 0.001 ; fig. 1a).

The unadjusted 4-year OS rates for patients with an ALC $\leq 1.0 \times 10^{9} / 1(\mathrm{n}=65)$ and patients with an ALC $>1.0 \times 10^{9} / 1(\mathrm{n}=164)$ were $47.0 \%(95 \%$ CI $32.4-60.3)$ and $79.4 \%$ (95\% CI 71.5-85.4), respectively ( $\mathrm{p}<0.001$; fig. 1b). The unadjusted 4-year OS rates for patients with an $A M C \geq 0.63 \times 10^{9} / 1(\mathrm{n}=48)$ and patients with an AMC $<0.63 \times 10^{9} / 1(\mathrm{n}=181)$ were $52.4 \%(95 \%$ CI $36.5-$ 66.2 ) and $75.6 \%$ (95\% CI 67.6-81.9), respectively ( $<$ 0.001 ; fig. 1c). In multivariate analyses, an ALC $\leq 1.0 \times$ $10^{9} / 1$ (HR 3.4, 95\% CI 2.1-5.6; $\mathrm{p}<0.001$ ) and an AMC $\geq 0.63 \times 10^{9} / 1$ (HR 2.6, 95\% CI 1.5-4.3; p < 0.001) were independently associated with inferior OS (table 2). Therefore, we combined these dichotomized variables to generate an 'immunological index' (IMI) and stratified patients into three risk groups: low (ALC $>1.0 \times 10^{9} / 1$ and $\left.\mathrm{AMC}<0.63 \times 10^{9} / \mathrm{l}\right)$, intermediate (ALC $\leq 1.0 \times 10^{9} / 1$ or AMC $\geq 0.63 \times 10^{9} / \mathrm{l}$ ) and high (ALC $\leq 1.0 \times 10^{9} / 1$ and $\left.\mathrm{AMC} \geq 0.63 \times 10^{9} / 1\right)$. The unadjusted 4 -year OS rates for patients with low- (L-IMI; $\mathrm{n}=128$ ), intermediate- (IIMI; $\mathrm{n}=89)$ and high-risk IMI (H-IMI; $\mathrm{n}=12)$ were 83.8\% (95\% CI 74.8-89.8), 59.3\% (95\% CI 47.1-69.5) and $18.8 \%$ (95\% CI 3.0-45.1), respectively ( $\mathrm{p}<0.001$; fig. 2a).

We next investigated whether IMI was associated with inferior OS independently of the IPI. Among the L-IPI and LI-IPI patients, the unadjusted 4-year OS rates for LIMI $(\mathrm{n}=100)$, I-IMI $(\mathrm{n}=33)$ and H-IMI $(\mathrm{n}=1)$ patients were $87.0 \%$ (95\% CI 77.4-92.7), 62.5\% (95\% CI $39.7-$ 78.7 ) and $100 \%$, respectively ( $\mathrm{p}=0.014$; fig. $2 \mathrm{~b}$ ). Among the HI-IPI and H-IPI patients, the unadjusted 4-year OS rates for L-IMI $(\mathrm{n}=28)$, I-IMI $(\mathrm{n}=56)$ and H-IMI $(\mathrm{n}=$ 11) patients were $71.0 \%$ (95\% CI 44.0-86.7), 56.0\% (95\% CI 41.1-68.5) and $10.4 \%$ (95\% CI 0.6-36.8), respectively ( $\mathrm{p}<0.001$; fig. 2c). Furthermore, multivariate analyses showed that HI-IPI or H-IPI (HR 1.9, 95\% CI 1.0-3.3; $\mathrm{p}=0.033)$, an ALC $\leq 1.0 \times 10^{9} / 1$ (HR 2.8, 95\% CI 1.6-4.7; $\mathrm{p}<0.001)$ and an AMC $\geq 0.63 \times 10^{9} / 1(\mathrm{HR} 2.2,95 \%$ CI $1.3-3.7 ; \mathrm{p}=0.005)$ were independently associated with inferior OS (table 2). 


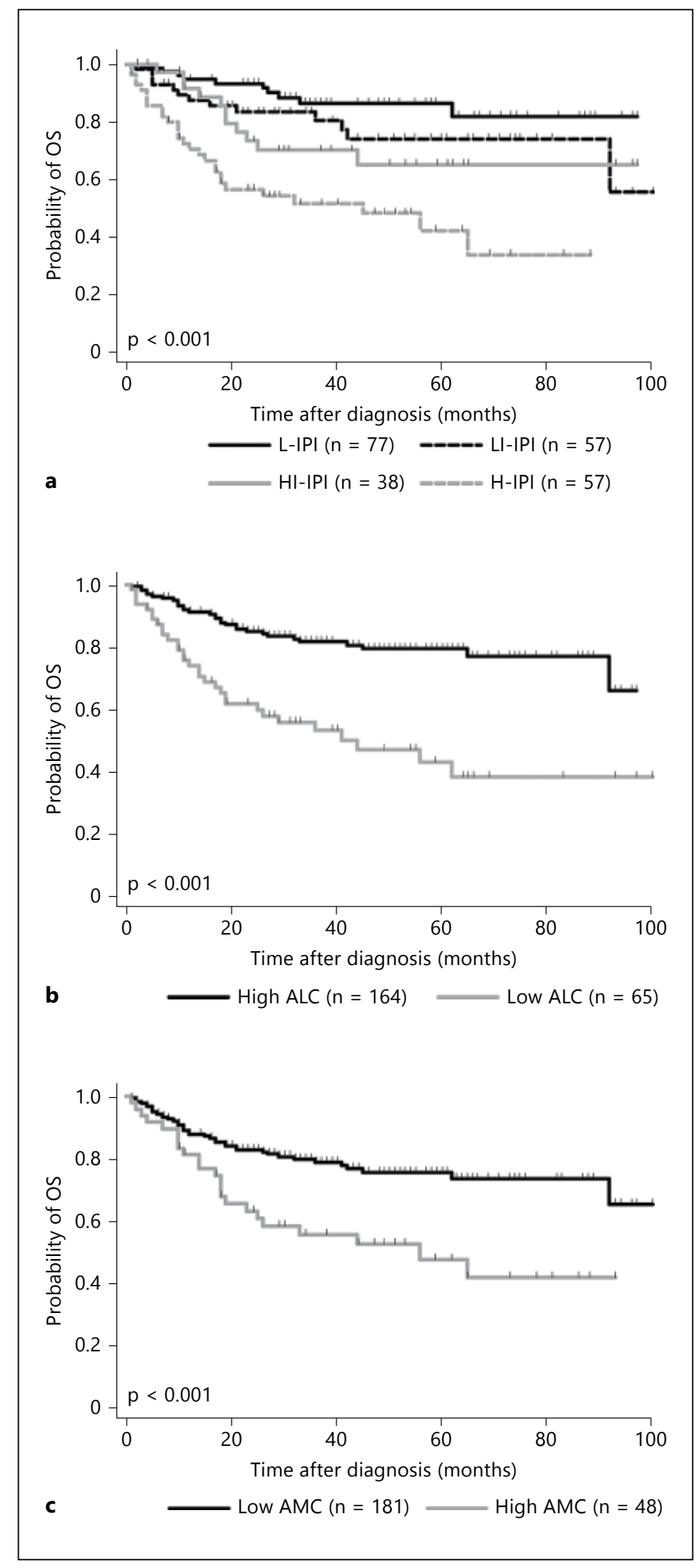

Fig. 1. The IPI, ALC and AMC predict the OS of patients with DLBCL in the rituximab era, respectively. a L-IPI, LI-IPI and HIIPI versus H-IPI. b ALC $>1.0 \times 10^{9} / \mathrm{l}$ (high ALC) versus ALC $\leq 1.0 \times$ $10^{9} / 1$ (low ALC). c AMC <0.63 × 109 / (low AMC) versus $\mathrm{AMC} \geq 0.63 \times 10^{9} / 1$ (high AMC).
Table 1. Characteristics of the 229 patients
Median age, years

Sex, female/male

Stage, I/II/III/IV

B symptom, -/+

Extranodal sites, $0-1 />1$

$\mathrm{LDH}$, normal/elevated

PS, 0-1/2-4

IPI, L/LI/HI/H

Median ALC, $\times 10^{9} / 1$

Median AMC, $\times 10^{9} / 1$
$69(23-90)$

$100 / 129$

$45 / 68 / 44 / 72$

$147 / 82$

$173 / 56$

$107 / 122$

$158 / 71$

$77 / 57 / 38 / 57$

$1.3(0.16-3.8)$

$0.39(0-2.4)$
Figures in parentheses are ranges. $\mathrm{LDH}=$ Lactate dehydrogenase; $\mathrm{PS}=$ performance status.

\section{Discussion}

The present study showed that in DLBCL patients receiving R-CHOP therapy, ALC and AMC were associated with inferior OS independently of the IPI, confirming data from a previous report [4]. The finding that AMC and ALC act as prognostic indicators can be explained by the following mechanisms: myeloid-derived cells, including monocytes and their progeny, contribute to the suppression of host antitumor immunity and play an important role in tumor angiogenesis, which in turn promotes tumorigenesis [5-7]; on the other hand, lymphopenia is a surrogate marker of host immunological incompetence [8]. In addition, lymphocytes (including natural killer cells) are important mediators of antibodydependent cell-mediated cytotoxicity and may be required for rituximab-mediated destruction of malignant B cells [9].

Given that in the rituximab era, the IPI cannot identify a population with an OS rate of $<50 \%$, the IMI could be a useful additional tool for predicting the prognosis of DLBCL patients; the 4-year OS rate for the H-IMI patients was $<20 \%$. Furthermore, compared with other more complicated and expensive methods such as gene expression profiling or interim positron emission tomography scans [10-12], the IMI is a very simple and low-cost tool for predicting the outcome of DLBCL patients. However, its efficacy was limited in the current study; only $5.1 \%(12 / 229)$ of patients were identified as H-IMI, whereas Wilcox et al. [4] (using the same model) identified $15.6 \%$ (40/256) of patients as H-IMI. This discrepancy might be ascribed to the difference in the value of AMC at diagnosis between the two patient cohorts. While an ALC cutoff of $1.0 \times 10^{9} / 1$ was used in previous studies, 


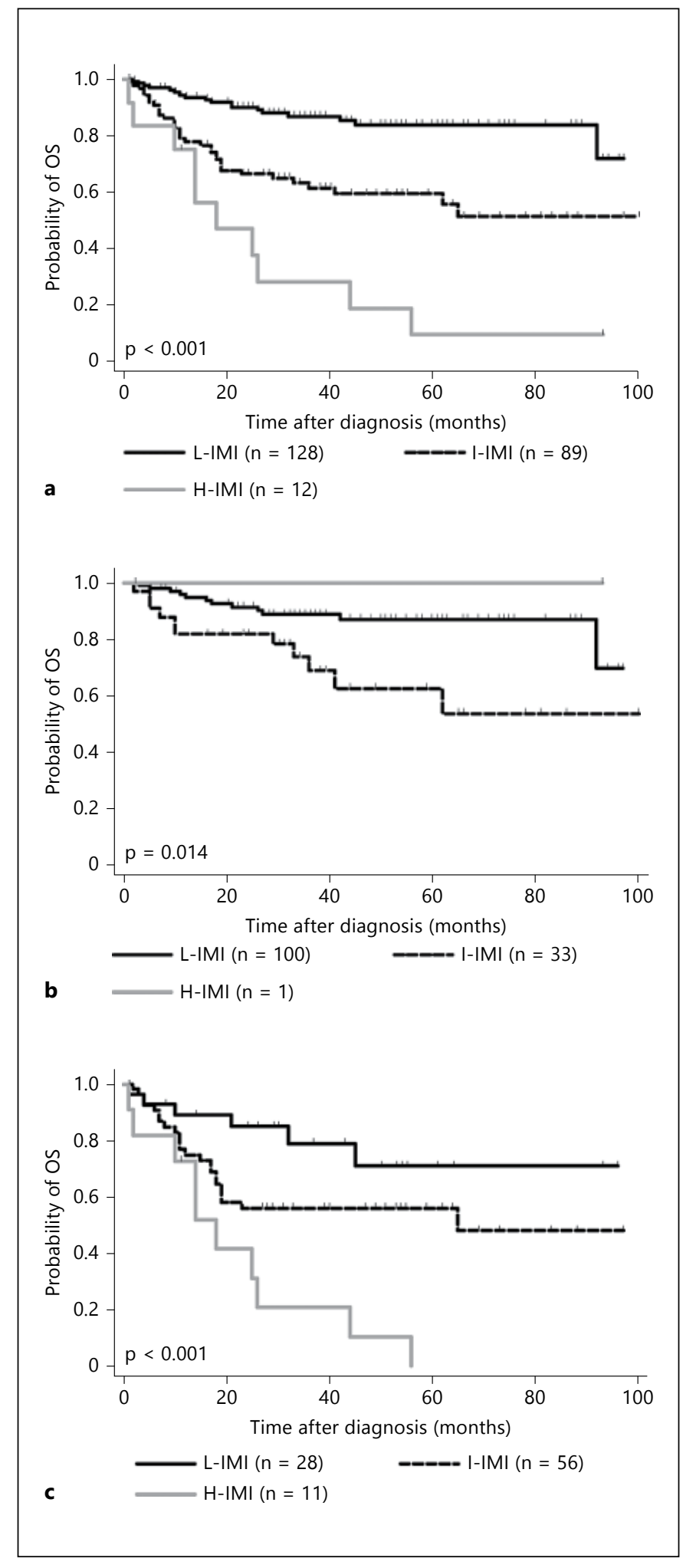

Fig. 2. The IMI predicts the OS for patients with DLBCL in the rituximab era. a All patients $(\mathrm{n}=229)$. b Low- and low-intermediate-risk patients identified by the IPI $(\mathrm{n}=134)$. (c) High-intermediate- and high-risk patients identified by the IPI $(n=95)$.
Table 2. Multivariate analyses

\begin{tabular}{llr}
\hline & HR & $\mathrm{p}$ \\
\hline Model I & & \\
$\quad$ ALC $\leq 1.0 \times 10^{9} / 1$ & $3.4(2.1-5.6)$ & $<0.001$ \\
AMC $\geq 0.63 \times 10^{9} / 1$ & $2.6(1.5-4.3)$ & $<0.001$ \\
Model II & & \\
HI-IPI or H-IPI & $1.9(1.0-3.3)$ & 0.033 \\
ALC $\leq 1.0 \times 10^{9} / 1$ & $2.8(1.6-4.7)$ & $<0.001$ \\
AMC $\geq 0.63 \times 10^{9} / 1$ & $2.2(1.3-3.7)$ & 0.005 \\
\hline
\end{tabular}

Figures in parentheses are $95 \%$ CIs.

the optimal cutoff point for the AMC has not been determined $[13,14]$. It is plausible that reducing the AMC cutoff point would identify a larger proportion of patients with a dismal prognosis. Indeed, if we reduced the AMC cutoff point to $0.50 \times 10^{9} / 1$, the unadjusted 4 -year OS rates for patients with L-IMI $(\mathrm{n}=105,45.9 \%)$, I-IMI $(\mathrm{n}=101$, $44.1 \%)$ and H-IMI $(\mathrm{n}=23,10.0 \%)$ were $86.4 \%(95 \% \mathrm{CI}$ 76.4-92.4), 62.9\% (95\% CI 51.7-72.1) and 32.6\% (95\% CI $12.3-54.9)$, respectively $(\mathrm{p}<0.001)$.

The results of this study should be interpreted cautiously, as it had several limitations; it was a retrospective study of a relatively small sample size, with a relatively short median follow-up period. Thus, these results should be validated in larger, prospective studies with a longer follow-up.

In conclusion, ALC and AMC at diagnosis may be useful for the prognostic stratification of patients with DLBCL in the rituximab era, particularly as they have the potential to identify patients at high risk of short survival. To improve the clinical outcome for high-risk patients identified by the ALC and the AMC, further investigation of new therapeutic strategies, targeting tumor-infiltrating lymphocytes and myeloid-derived cells, are warranted.

\section{Acknowledgements}

We are indebted to all the physicians at the Kobe City Medical Center General Hospital. This work was supported by the Kasahara Memorial Foundation for Medical Research.

\section{Disclosure Statement}

The authors declare no conflict of interest. 


\section{References}

-1 Ziepert M, Hasenclever D, Kuhnt E, Glass B, Schmitz N, Pfreundschuh M, Loeffler M: Standard International Prognostic Index remains a valid predictor of outcome for patients with aggressive CD20+ B-cell lymphoma in the rituximab era. J Clin Oncol 2010;28: 2373-2380.

$>2$ Dave SS, Wright G, Tan B, Rosenwald A, Gascoyne RD, Chan WC, Fisher RI, Braziel RM, Rimsza LM, Grogan TM, Miller TP, LeBlanc M, Greiner TC, Weisenburger DD, Lynch JC, Vose J, Armitage JO, Smeland EB, Kvaloy S, Holte H, Delabie J, Connors JM, Lansdorp PM, Ouyang Q, Lister TA, Davies AJ, Norton AJ, Muller-Hermelink HK, Ott G, Campo E, Montserrat E, Wilson WH, Jaffe ES, Simon R, Yang L, Powell J, Zhao H, Goldschmidt N, Chiorazzi M, Staudt LM: Prediction of survival in follicular lymphoma based on molecular features of tumor-infiltrating immune cells. N Engl J Med 2004;351:21592169.

>3 Lenz G, Wright G, Dave SS, Xiao W, Powell J, Zhao H, Xu W, Tan B, Goldschmidt N, Iqbal J, Vose J, Bast M, Fu K, Weisenburger DD, Greiner TC, Armitage JO, Kyle A, May L, Gascoyne RD, Connors JM, Troen G, Holte H, Kvaloy S, Dierickx D, Verhoef G, Delabie J, Smeland EB, Jares P, Martinez A, LopezGuillermo A, Montserrat E, Campo E, Braziel RM, Miller TP, Rimsza LM, Cook JR, Pohlman B, Sweetenham J, Tubbs RR, Fisher RI, Hartmann E, Rosenwald A, Ott G, MullerHermelink HK, Wrench D, Lister TA, Jaffe ES, Wilson WH, Chan WC, Staudt LM: Stromal gene signatures in large-B-cell lymphomas. N Engl J Med 2008;359:2313-2323.
4 Wilcox RA, Ristow K, Habermann TM, Inwards DJ, Micallef IN, Johnston PB, Colgan JP, Nowakowski GS, Ansell SM, Witzig TE, Markovic SN, Porrata L: The absolute monocyte and lymphocyte prognostic score predicts survival and identifies high-risk patients in diffuse large-B-cell lymphoma. Leukemia 2011;25:1502-1509.

5 Takasaki Y, Iwanaga M, Tsukasaki K, Kusano M, Sugahara K, Yamada Y, Kamihira S, Ikeda $\mathrm{S}$, Tomonaga $\mathrm{M}$ : Impact of visceral involvements and blood cell count abnormalities on survival in adult T-cell leukemia/lymphoma (ATLL). Leuk Res 2007;31:751-757.

6 Gabrilovich DI, Nagaraj S: Myeloid-derived suppressor cells as regulators of the immune system. Nat Rev Immunol 2009;9:162-174.

7 Wilcox RA, Feldman AL, Wada DA, Yang ZZ, Comfere NI, Dong H, Kwon ED, Novak AJ, Markovic SN, Pittelkow MR, Witzig TE, Ansell SM: B7-H1 (PD-L1, CD274) suppresses host immunity in T-cell lymphoproliferative disorders. Blood 2009;114:2149-2158.

$>8$ Shivakumar L, Ansell S: Targeting B-lymphocyte stimulator/B-cell activating factor and a proliferation-inducing ligand in hematologic malignancies. Clin Lymphoma Myeloma 2006;7:106-108.

$>9$ Weiner GJ: Rituximab: mechanism of action. Semin Hematol 2010;47:115-123.
10 Jardin F, Jais JP, Molina TJ, Parmentier F, Picquenot JM, Ruminy P, Tilly H, Bastard C, Salles GA, Feugier P, Thieblemont C, Gisselbrecht C, de Reynies A, Coiffier B, Haioun C, Leroy K: Diffuse large B-cell lymphomas with CDKN2A deletion have a distinct gene expression signature and a poor prognosis under R-CHOP treatment: a GELA study. Blood 2010;116:1092-1104.

11 Montes-Moreno S, Martinez N, Sanchez-Espiridion $B$, Diaz Uriarte $R$, Rodriguez ME, Saez A, Montalban C, Gomez G, Pisano DG, Garcia JF, Conde E, Gonzalez-Barca E, Lopez A, Mollejo M, Grande C, Martinez MA, Dunphy C, Hsi ED, Rocque GB, Chang J, Go RS, Visco C, Xu-Monette Z, Young KH, Piris MA: miRNA expression in diffuse large B-cell lymphoma treated with chemoimmunotherapy. Blood 2011;118:1034-1040.

12 Safar V, Dupuis J, Itti E, Jardin F, Fruchart C, Bardet S, Vera P, Copie-Bergman C, Rahmouni A, Tilly H, Meignan M, Haioun C: Interim [18F]fluorodeoxyglucose positron emission tomography scan in diffuse large B-cell lymphoma treated with anthracycline-based chemotherapy plus rituximab. J Clin Oncol 2012; 30:184-190.

13 Song MK, Chung JS, Seol YM, Kim SG, Shin HJ, Choi YJ, Cho GJ, Shin DH: Influence of low absolute lymphocyte count of patients with nongerminal center type diffuse large Bcell lymphoma with R-CHOP therapy. Ann Oncol 2010;21:140-144.

14 Kim DH, Baek JH, Chae YS, Kim YK, Kim HJ, Park YH, Song HS, Chung JS, Hyun MS, Sohn SK: Absolute lymphocyte counts predicts response to chemotherapy and survival in diffuse large B-cell lymphoma. Leukemia 2007; 21:2227-2230. 